\title{
The Impact of Augmented Reality on the Social Skills of Children with High Functioning Autism
}

\section{| Morteza Bakhtiarvand |}

\author{
Ph.D.student of Educational \\ Technology, Department of \\ Educational Technology, \\ Faculty of Psychology and \\ Education, Allameh Tabataba'i \\ University, Tehran, Iran \\ m_bakhtiarvand@yahoo.com
}

DOI: https://doi.org/10.47175/rissj.v2i2.227

\section{INTRODUCTION}

Autism is a disorder that is affecting more and more people (Allen, Bulls, Weber, 2013). It is characterized by severe impairment in social skills and repetitive and limited behaviors, and is clinically divided into three subtypes: Level One, Level Two, and Level Three (American Psychiatric Association, 2015). In terms of etiology, most scientists who study autism believe that there is no single cause for this disorder, but there are many reasons for autism (Willie, 2012). The prevalence of autism has increased rapidly in recent years (World Health Organization, 2016).

In terms of diagnostic symptoms, autism disorder in the fifth edition of the Diagnostic and Statistical Manual of Mental Disorders instead of 3 Diagnostic Signs: Defects in Social Interactions, Communication Defects and Behavioral Problems, in two areas: Defects in Communication and Social Interactions and Behaviors, Interests And limited and repetitive activities are reduced, and in this edition there is no need for diagnostic criteria for delays in language development (American Psychiatric Association, 2013).

Children with autism are resistant to change and insist on maintaining uniformity, have difficulty expressing their needs, and use gestures instead of words (Bailey, 2012). These children are hypersensitive or too sensitive to sensory stimuli (such as sound and pain). For example, if they say his name out loud, they don't answer, but at the same time, they pay attention to the following sound. Many sounds, lights, and tastes that are not annoying or unpleasant to other children may be annoying, annoying, and even painful for children with autism (Mash and Wolf, 2008). The prevalence of autism in children is 1 in 59 births. (Centers for Disease Control and Prevention, 2018). In Iran, according to research, the prevalence of this disorder has been reported to be 95.2 in 10,000 (Samadi, McKangi, 2015). 
Deficiency in social skills is the main and most important feature of autism disorder (Witt, Keoing Vaskahil, 2007). Deficiency in social skills not only prevents the development of children with autism, but also leads to their rejection and rejection by friends, peers and adults and their isolation and isolation (Delano and Snell, 2006). Deficiencies in social skills in these people include problems at the beginning of social interactions, continued relationship, sharing pleasure and happiness, taking perspective and understanding the interests of others (Witt, et al., 2007). Disadvantages of social skills include poor academic achievement, social failure, anxiety, depression, abuse, social barriers and social isolation (Bilini, Peters, Banner \& Hope, 2007; Quoted from Golzari and Hemmati Alamdarloo, 2015).

One of the ways to improve children's social skills is to use augmented reality intervention program. On the other hand, today, due to the presence of amazing technological phenomena, learning and teaching have become more real, more practical and more pleasant, and their quality and efficiency have improved. Found. The rapid development of these technology-based tools and their adaptation to human needs has led to the formation of interactive, active and creative learning environments. (Grab and Grab, 2007). And the augmented reality of these technologies allows people to have a combination of real and virtual worlds on a mobile phone or tablet and learn in a desired learning environment. Augmented reality is one of the newest technological potentials used in education; and various studies have been done in recent years according to the ability of this tool to create a powerful educational-learning environment in different scientific fields and at different ages (Ronhovern and Johnson, 2018).

Augmented reality brings many learning opportunities and helps challenge the "science for all" challenge, namely providing scientific educational opportunities tailored to diverse and heterogeneous populations. Unlike virtual environments that completely immerse users in a virtual world, augmented reality combines the real world with artificial computergenerated components. The combination of real and virtual information, as a new type of user experience, has shown a positive effect on intrinsic motivation as well as learning cognitive and social skills (Mir Moeini, 2017).

Augmented reality enables the instructor to share his knowledge with students through images that are based on the facts in the classroom. Through the digital human body model shown in 3D, the instructor can access any kind of information about the desired elements and each of the parts separately to show the details, even people can develop any kind of activity. Interact with the model; (Ibanes, Disrio, Villarreal and Kloss, 2014).

Tobias (2014) examined the effect of using computer software on improving interactive skills in children with autism spectrum disorder. The study involved three children with autism spectrum disorder. The results of this study showed that computer software is effective in improving interactive skills. In addition, Weiner and Ingrosell (2010) examined the use of various computer programs in increasing communication skills in children with autism spectrum disorder. The results of their research showed that the use of computer programs has a beneficial effect on increasing communication skills in people with autism spectrum disorder.

Therefore, the aim of this study was to determine the effectiveness of augmented reality on the social skills of children with the disorder Tissue is highly functional.

\section{RESEARCH METHODS}

The present study was a quasi-experimental study with a posttest test with a control group. The statistical population of the present study included all children with autism with high performance in Andimeshk in 1398. 
Participants included 20 children with high-functioning autism disorder who were selected by available sampling method and randomly assigned to two experimental groups (10 subjects) and control subjects (10 subjects). Criteria for entering the study included a definitive diagnosis of high-functioning autism disorder (based on clinical interviews with symptoms of autism, non-simultaneous direct or indirect intervention aimed at teaching social skills, conscious satisfaction, and a willingness to cooperate with children and their families). This was the case. The criteria for leaving the study included not cooperating with the family during treatment and the number of absences was more than one session. The research instruments included the following:

\section{Research Instruments}

1. Clinical interview with the symptoms of autism

Clinical interviews based on the criteria of the fifth edition of the Diagnostic and Statistical Manual of Disorders (2013) were used to reassure children with highfunctioning autism disorder (Level One).

2. Bellini's social profile: This study will use Bellini's social profile to measure social skills. Bellini's Social Profile (2007) has 48 four-point questions with three subscales, reciprocal social behavior (20 questions and a score of 0.90$)$, social participation (11 questions and a score of 0.89 ), and mature and appropriate social behavior (17 questions with a score of 86). 0) (quoted by Rezaei, 1396). Rezaei (2013) reported that the validity of the test was $89 \%$ by Cronbach's alpha method and in terms of validity, the content validity of this test was confirmed according to the theory proposed by experts at the highest level. The overall correlation of the scale with the subscale $89 \%$ have been reported (Rezaei, 1396).

\section{Procedure}

Before conducting the research, the Bellini Social Profile Added Program was implemented, and then a briefing session was held at the center to help parents of children with autism with high performance disorder, and the researchers described the benefits of augmented reality program research for children with the disorder. They performed autism with high performance. And the augmented reality intervention program was implemented in $1045-$ minute sessions on the experimental group. If the control group receives such an intervention program. In the end, both groups were re-evaluated by Blini's social profile.

\section{RESULTS AND DISCUSSION}

The findings were analyzed using covariance analysis.

Table 1. Average and standard deviation of social skills scores in two measurement stages by experimental and control group

\begin{tabular}{lllcc}
\hline Variable & Group & Level & Mean & Standard Deviation \\
\hline Social Skills & Control & Pre-test & 36.36 & 6.845 \\
Social Skills & Control & Post-test & 36.77 & 6.732 \\
Social Skills & Experimental & Pre-test & 36.98 & 7.606 \\
Social Skills & Experimental & Post-test & 39.39 & 5.098 \\
\hline
\end{tabular}

Table 1 shows the descriptive statistics for the mean and standard deviation of social skills scores for children in the experimental and control groups in two stages of assessment (pretest and post-test). As can be seen, in the control group, the mean scores in the pre-test and post-test stages do not change much, but in the experimental group, we see more scores in the post-test than in the pre-test. 
In order to investigate the effectiveness of augmented reality on the social skills of children with autism with high performance, a covariance test (ANCOVA) was used. Prior to this test, the statistical assumptions of the normality of the score distribution using the Kolmogorov-Smirnov test, the uniformity of the regression line slope, and the homogeneity of the variances were examined using the Levine test, which did not violate the above assumptions. The use of covariance analysis test is not prohibited.

Table 2. Results of analysis of covariance to compare social skills in the experimental group and control group

\begin{tabular}{lllllll}
\hline $\begin{array}{l}\text { The Source } \\
\text { of Changes }\end{array}$ & $\begin{array}{l}\text { Total } \\
\text { Square }\end{array}$ & $\begin{array}{l}\text { Degree of } \\
\text { Freedom }\end{array}$ & $\begin{array}{l}\text { Average } \\
\text { Squares }\end{array}$ & $\begin{array}{l}\text { The Value } \\
\text { of F }\end{array}$ & $\begin{array}{l}\text { Significance } \\
\text { Level }\end{array}$ & $\begin{array}{l}\text { Effect } \\
\text { Size }\end{array}$ \\
\hline Pre-test & 354.747 & 1 & 354.765 & 193.786 & 0.001 & 0.876 \\
Social Skills & 12.739 & 1 & 12.876 & 6.850 & 0.027 & 0.765 \\
Error & 16.486 & 9 & 1.8765 & $\ldots \ldots \ldots$ & $\ldots \ldots \ldots$ & $\ldots \ldots$ \\
Total & 377.687 & 11 & $\ldots \ldots \ldots$. & $\ldots \ldots \ldots$. & $\ldots \ldots \ldots$ & $\ldots \ldots \ldots$ \\
\hline
\end{tabular}

Table 2 shows the results of the covariance analysis test to compare the scores of social skills in the experimental and control groups in the posttest stage. The value of $\mathrm{F}$ obtained is equal to 6.963 and is significant at the alpha level of 0.05 ( $\mathrm{p}<0.05)$. Therefore, the null hypothesis is rejected and the research hypothesis is confirmed. Given the higher mean scores of the experimental group in the post-test, it can be concluded that augmented reality affects the social skills of children with autism with high performance.

Table 3. Average adjusted mean scores after social skills test

\begin{tabular}{lll}
\hline Group & Mean & Standard Error \\
\hline Control & 37.333 & 0.556 \\
Experimental & 39.566 & 0.554 \\
\hline
\end{tabular}

As can be seen in Table 3, the average social skills of the experimental group (39.566) after adjusting the pre-test scores were higher than the control group (37.333), which shows the effect of added reality on social skills. Children with autism have high performance.

\section{Discussion}

The present study determined the effectiveness of augmented reality on the social skills of children with autism with high performance. The findings show that augmented reality has influenced the social skills of children with high-functioning autism.

These findings are in line with Tobias' (2014) research, which showed that computer software is effective in improving children's interactive skills with autism. And Weiner and Ingrosell (2010) showed that the use of computer programs has a beneficial effect on increasing communication skills in people with autism spectrum disorder.

In order to explain these findings, it should be said that the use of technology allows a person to develop skills in a controlled, standardized and predictable environment, and at the same time allows people to pay attention to your ability and speed levels (Glan, BaronCohen, 2007). Due to the fact that children with autism have problems in unpredictable social environments. This feature of technology can be useful for these people. Technology encourages people to play an active role in education and to directly manipulate the intervention program.

In general, the findings of the present study showed that augmented reality improves the social skills of children with high-functioning autism disorder. $\mathrm{O}$ augmented reality. Therefore, it is worthwhile to be careful in generalizing the results. 


\section{CONCLUSION}

The use of augmented reality technology is a promising option for teaching social and communication skills to students with autism spectrum disorders. In this way, teachers can use it to maintain presence or attention when they have difficulty with video or video modeling. The relative novelty of augmented reality technology and its use as an educational tool for special education still needs further research. Similar to this study can be used to evaluate the effectiveness of augmented reality for people with autism spectrum disorder in different age groups and for different skills or people with mental and developmental disabilities.

\section{REFERENCES}

Allen, K. A., Bowles, T. V., \& Weber, L. L. (2013). Mothers and Fathers Stress Associated with Parenting a Child with Autism Spectrum Disorder. Autism Insights, 5(1):1-11.

American Psychiatric Association. (2013). Diagnostic and statistical manual of mental disorders (DSM-5). American Psychiatric Pub.

Bailey, M. (2012). Social skill intervention strategies for children with autism. Psychological Record, 60(2), 389-406.

Centre for Disease Control and Prevention. (2018). identified prevalence of Autism spectrum disorder: ADDM network 2000-2010, combining data from all site. http://www.cdc.gov/ncbddd/autism/data.html.

Delano, M., \& Snell, M. E. (2006). The effects of social stories on the social engagement of children with autism. Journal of Positive Behaviour Interventions, 8(1), 2942.

Grabe, M. \& Grabe, C. (2007) (5th Ed.) Integrating technology for meaningful learning. Boston: Houghton Mifflin Company.

Ibáñez, M. B., Di Serio, Á. Villarán, D., \& Kloos, C. D. (2014). Experimenting with electromagnetism using augmented reality: Impact on flow student experience and educational effectiveness. Computers \& Education, 71, 1-13.

Mir Moeini, Simeh Sadat; Balghizadeh, Susan and Asgari, Afsaneh (1396). Augmented Reality and Its Role in Mathematics Education ", 15th Conference on Iranian Mathematics Education, 21-2.

Revenhorn, K., \& Jansén, P. (2018). Augmented reality ochdess pedagogiska implikationer: en analys baserad påett sociokulturellt perspektiv.

Rezaei, Saeed. (2017). Compilation of Social Skills Teaching Programme and Survey of its effectiveness on Autistic Children. The Journal of Learning Disorders. 6(4). 68-82

Samadi, S. A. \& McConkey, R. (2015). Screening for autism in Iranian preschoolers: Contrasting M-CHAT and a scale developed in Iran. Journal of autism and developmental disorders, 45(9), 2908-2916.

Tobias, E. F. (2014 the effect of using a specific computer program on the social behavior of elementary school students who have been diagnosed with Autism Spectrum Disorder

Wainer, A. L., \& Ingersoll, B. R. (2011). The use of innovative computer technology for teaching social communication to individuals with autism spectrum disorders. Research in Autism Spectrum Disorders, 5(1), 96-107.

White, S. W. Keoing, K. \& Scahill, L. (2007). Social skills development in children with autism spectrum disorders: A review of the intervention research. Journal of Autism and Developmental Disorders, 37(10), 1858-1868.

Williams, C., Wright, B., Callaghan, G., \& Coughlan, B. (2002). Do children with autism learn to read more readily by computer assisted instruction or traditional book methods? Autism, 6, 71-91. 